\title{
Dynamic aspects of oxygen consumption and carbon dioxide production in swine
}

\author{
BY J. VAN MILGEN ${ }^{1}$, J. NOBLET ${ }^{1}$, S. DUBOIS ${ }^{1}$ AND J.-F. BERNIER ${ }^{2}$ \\ ${ }^{1}$ Institut National de la Recherche Agronomique, Station de Recherches Porcines, 35590 Saint-Gilles, \\ France \\ ${ }^{2}$ Département des Sciences Animales, Université Laval, Ste-Foy, Québec, GIK 7P4, Canada
}

(Received 23 July 1996-Revised 21 February 1997-Accepted 3 March 1997)

\begin{abstract}
A model is proposed that allows study of the short-term dynamics of gas exchanges (and heat production) in large open-circuit respiration chambers. The model describes changes in $\left[\mathrm{O}_{2}\right]$ and $\left[\mathrm{CO}_{2}\right]$ in the respiration chamber by a series of differential equations based on animal metabolism and physical characteristics of gas exchange. The model structure was similar for $\mathrm{O}_{2}$ and $\mathrm{CO}_{2}$, although model parameters differed. A constant level of $\mathrm{O}_{2}$ consumption (and $\mathrm{CO}_{2}$ production) was assumed for resting animals which was different for fed and fasted animals. The adaptation from a fed to a fasting state was described as a first-order process. Physical activity (standing or sitting) was recorded and was included in the model as a constant. Thermic effect of feed comprised the $\mathrm{O}_{2}$ consumption and $\mathrm{CO}_{2}$ production related to several relatively rapidly occurring processes after ingestion of a meal (e.g. ingestion, digestion or absorption). In the model, these processes were pooled into a single phenomenon. Model parameters were obtained statistically by comparing model predictions (based on the numerically integrated differential equations) with the observed $\left[\mathrm{O}_{2}\right]$ and $\left[\mathrm{CO}_{2}\right]$. The model was evaluated by studying gas exchanges in growing pigs that were fasted for $31 \mathrm{~h}$ and re-fed a single meal thereafter. The model fitted the data well over the $47 \mathrm{~h}$ measurement range. Traditional methods in which heat production is calculated suffer from noisy data when the interval between observations becomes too short. The proposed method circumvents this by modelling the observed concentration of gases in the respiration chamber rather than the calculated heat production.
\end{abstract}

Energy metabolism: Calorimetry: Modelling

Animals produce heat from a variety of metabolic processes such as maintenance, thermoregulation, physical activity and production (e.g. deposition of body tissue, milk production). Indirect calorimetry has played an important role in measuring this heat production in both animals and human subjects. In open-circuit respiration chambers, heat production can be calculated based on measurements of $\mathrm{O}_{2}$ consumption and $\mathrm{CO}_{2}$ production without hampering the normal behaviour of the animal (Brown et al. 1984). Due to the size of the respiration chamber in relation to the subject of study, the technique has been of limited use in studying the short-term dynamics of energy metabolism. An instantaneous change in $\mathrm{O}_{2}$ consumption (or $\mathrm{CO}_{2}$ production) by the subject results in a small and prolonged response at the gas analyser. The limited sensitivity of gas analysers in combination with the large volume of the respiration chamber and short interval between measurements leads to noisy data when heat production is calculated (McLean \& Watts, 1976; Brown et al. 1984; McDonald et al. 1988).

The objective of the present study was to propose an alternative method to study the dynamics of gas exchange in open-circuit respiration chambers. In traditional methods, 
data for $\left[\mathrm{O}_{2}\right]$ and $\left[\mathrm{CO}_{2}\right]$ are used in the algebraic calculation of gas exchanges and the resulting heat production. The latter can then be regressed $v$. a series of observations (e.g. time, activity, ingestion of a meal) using an 'animal' model. In the proposed method, it is not the calculated heat production but the observed changes in gas concentrations that are regressed $v$. the observations, using both an 'animal' model as well as a 'respiration chamber' model. This approach circumvents the calculation of heat production based on observations, as predicted values for $\left[\mathrm{O}_{2}\right]$ and $\left[\mathrm{CO}_{2}\right]$ are compared directly with observed values.

\section{MATERIALS AND METHODS}

The approach taken in this study was to identify components of $\mathrm{O}_{2}$ consumption and $\mathrm{CO}_{2}$ production by the animal in a model and to estimate, statistically, parameters of this model in order to obtain a suitable fit to observed data for $\left[\mathrm{O}_{2}\right]$ and $\left[\mathrm{CO}_{2}\right]$ in the respiration chamber. The model is described by a series of differential equations based on animal metabolism and physical characteristics of gas exchange in the respiration chamber. The differential equations are integrated numerically and then serve in a statistical optimization function. If desired, heat production may be calculated as an auxiliary function of estimated parameters.

\section{Equipment}

Two open-circuit respiration chambers of approximately 2 and $12 \mathrm{~m}^{3}$ respectively were used based on a design similar to that of Vermorel et al. (1973). The respiration chambers were air-conditioned to maintain constant temperature $\left(26.0(\mathrm{SD} 0 \cdot 1)^{\circ}\right)$ and humidity $(70 \%$ relative humidity) during the experiment. Each chamber contained an individual metabolism cage equipped with two infrared detectors to detect physical activity of the animal. Interruption of an infrared beam for at least $20 \mathrm{~s}$ was considered to be a physical activity (i.e. standing or sitting) of the animal. Weight of the feeder was measured continuously. The chambers were lit between 08.00 and 20.00 hours.

Gas was extracted continuously from the respiration chamber by an exhaust fan which was assumed to have a constant extraction rate. Due to the extraction of gas and the limited opening of the gas inlet, the pressure in the respiration chamber was approximately $1 \mathrm{kPa}$ lower than the atmospheric pressure. This underpressure ensured that no gas leakage occurred from the respiration chamber. Temperatures (at the gas meter and in the respiration chamber) and atmospheric pressure were measured continuously. Variations in the atmospheric pressure and temperature were used to calculate the standard temperature and pressure (STP; $0^{\circ}, 101 \mathrm{kPa}$ ) extraction rate. Unless stated otherwise, all volumes were calculated as STP volumes.

The $\left[\mathrm{O}_{2}\right]$ was measured with paramagnetic differential $\mathrm{O}_{2}$ analyser (Oxygor $6 \mathrm{~N}$, Maihak AG, Hamburg, Germany) whereas $\left[\mathrm{CO}_{2}\right]$ was measured with an absorption infrared analyser (Unor $6 \mathrm{~N}$, Maihak AG, Hamburg, Germany). The analysers had a range of measurement of 0.01 (e.g. $0.20-0.21$ for $\left[\mathrm{O}_{2}\right]$ and $0.00-0.01$ for $\left[\mathrm{CO}_{2}\right]$ ) with a sensivity of $0.2 \%$ within the measurement range. The analysers were calibrated daily with a gas of known composition. Gas concentrations were measured between 50 and 60 times/s. To reduce data volume, $10 \mathrm{~s}$ averages were stored on a microcomputer awaiting further analysis. Gases other than $\mathrm{O}_{2}$ and $\mathrm{CO}_{2}$ (primarily $\mathrm{N}_{2}$ ) were calculated as $\left[\mathrm{N}_{2}\right]=$ $1-\left[\mathrm{O}_{2}\right]-\left[\mathrm{CO}_{2}\right]$. 
Verification of the whole system was performed monthly through gravimetry by infusing either $\mathrm{CO}_{2}$ or $\mathrm{N}_{2}$ (to simulate $\mathrm{O}_{2}$ consumption) in the respiration chamber. After attaining a steady-state for $\left[\mathrm{O}_{2}\right]$ and $\left[\mathrm{CO}_{2}\right]$ at the gas analysers, the measured ${ }^{\prime} \mathrm{O}_{2}$ consumption' and $\mathrm{CO}_{2}$ production were compared with the infused quantities. The system was considered operational when the deviation was less than $1 \%$.

\section{Physical aspects of gas exchange}

In the traditional methods, heat production is calculated based on $\mathrm{O}_{2}$ consumption and $\mathrm{CO}_{2}$ production (Brouwer, 1965). In the case of $\mathrm{O}_{2}$ the volume consumed $\left(\dot{\mathrm{V}}_{\mathrm{O}_{2} \text {,consumption }}\right.$; litres $/ \mathrm{h})$ is calculated as the difference between the inflow $\left(\dot{\mathrm{V}}_{\mathrm{O}_{2} \text {,in }} ;\right.$ litres $\left./ \mathrm{h}\right)$ and outflow $\left(\dot{\mathrm{V}}_{\mathrm{O}_{2} \text { out }} ;\right.$ litres $\left./ \mathrm{h}\right)$ minus the change in volume of gas in the chamber $\left(\dot{\mathrm{V}}_{\mathrm{O}_{2} \text {, chamber }} ;\right.$ litres $\left./ \mathrm{h}\right)$ between two successive measurements (Vermorel et al. 1973; Brown et al. 1984; Verstegen et al. 1987):

$$
\dot{\mathrm{V}}_{\mathrm{O}_{2}, \text { consumption }}=\dot{\mathrm{V}}_{\mathrm{O}_{2} \text {,in }}-\dot{\mathrm{V}}_{\mathrm{O}_{2} \text {,out }}-\dot{\mathrm{V}}_{\mathrm{O}_{2} \text {, hhamber }} .
$$

The notation $\dot{V}$ indicates the first derivative of $V$ with respect to time (i.e., $\dot{V}=\partial V / \partial t$ ). The $\dot{\mathrm{V}}_{\mathrm{O}_{2} \text {,chamber }}$ is calculated as the product of volume of gas in the respiration chamber and the rate of change in $\left[\mathrm{O}_{2}\right]$ between successive measurements (i.e. $\dot{\mathrm{V}}_{\mathrm{O}_{2} \text {, chamber }}=\mathrm{V}_{\text {gas, chamber }} \partial\left[\mathrm{O}_{2}\right] / \partial \mathrm{t}$ ). It is evident that when $\partial \mathrm{t}$ approaches zero, one has to measure infinitesimal changes in $\partial\left[\mathrm{O}_{2}\right]$ to maintain precision of $\dot{\mathrm{V}}_{\mathrm{O}_{2} \text {,chamber }}$ and thus $\dot{\mathrm{V}}_{\mathrm{O}_{2}, \text { consumption }}$.

The proposed model of the respiration chamber was based on a series of differential equations describing the change in volume of $\mathrm{O}_{2}, \mathrm{CO}_{2}$ and other gases (primarily $\mathrm{N}_{2}$ ). Similar to Equation (1), the changes in volume of $\mathrm{O}_{2}, \mathrm{CO}_{2}$, and $\mathrm{N}_{2}$ can be described by:

$$
\begin{aligned}
\dot{\mathrm{V}}_{\mathrm{O}_{2}, \text { chamber }} & =\dot{\mathrm{V}}_{\mathrm{O}_{2} \text {,in }}-\dot{\mathrm{V}}_{\mathrm{O}_{2}, \text { out }}-\dot{\mathrm{V}}_{\mathrm{O}_{2}, \text { consumption }}, \\
\dot{\mathrm{V}}_{\mathrm{CO}_{2} \text {,chamber }} & =\dot{\mathrm{V}}_{\mathrm{CO}_{2} \text {,in }}-\dot{\mathrm{V}}_{\mathrm{CO}_{2} \text {,out }}+\dot{\mathrm{V}}_{\mathrm{CO}_{2}, \text { production }}, \\
\dot{\mathrm{V}}_{\mathrm{N}_{2} \text {, chamber }} & =\dot{\mathrm{V}}_{\mathrm{N}_{2} \text {,in }}-\dot{\mathrm{V}}_{\mathrm{N}_{2}, \text { out }} .
\end{aligned}
$$

The volume of these gases can be obtained through numerical integration of these equations with respect to time. The total volume of gas in the chamber is:

$$
\mathrm{V}_{\text {gas, chamber }}=\mathrm{V}_{\mathrm{O}_{2} \text {, chamber }}+\mathrm{V}_{\mathrm{CO}_{2} \text {, chamber }}+\mathrm{V}_{\mathrm{N}_{2} \text {, chamber }} \text {, }
$$

from which the gas concentrations were calculated (e.g. $\left[\mathrm{O}_{2}\right]=\mathrm{V}_{\mathrm{O}_{2} \text {,chamber }} / \mathrm{V}_{\mathrm{gas}, \text { chamber }}$ ).

In open-circuit calorimetry, only the outflow of gas is measured. The instantaneous inflow was determined by comparing the STP equivalent of the physical volume of the respiration chamber $\left(\mathrm{V}_{\text {physical,chamber }}\right)$ with $\mathrm{V}_{\mathrm{gas}, \text { chamber }}$ so that:

$$
\ddot{\mathrm{V}}_{\text {in }}=\left(\mathrm{V}_{\text {physical,chamber }} \frac{273.15 \times \mathrm{P}_{\text {chamber }}}{\mathrm{T}_{\text {chamber }}}\right)-\mathrm{V}_{\text {gas, chamber }} \text {, }
$$

where $T_{\text {chamber }}$ is the temperature in the respiration chamber $\left({ }^{\circ} \mathrm{K}\right)$ and the $P_{\text {chamber }}$ is the pressure in the respiration chamber (atm). The inflow for each gas is then the product of $\dot{\mathrm{V}}_{\text {in }}$ and the fraction of these gases in the environment $\left(\mathrm{O}_{2}: 0.2095, \mathrm{CO}_{2}: 0.0003, \mathrm{~N}_{2}: 0.7902\right)$.

To estimate $\mathrm{V}_{\text {physical,chamber }}$ precisely, a procedure similar to the monthly system verification was used. $\mathrm{N}_{2}$ or $\mathrm{CO}_{2}$ was infused at a constant rate in the respiration chamber, which was fully equipped but did not contain any animals. The differential equations 
describing the change in volume of the gases were modified to accommodate the infusion of either $\mathrm{CO}_{2}$ or $\mathrm{N}_{2}$.

$$
\begin{aligned}
\dot{\mathrm{V}}_{\mathrm{O}_{2}, \text { chamber }} & =\dot{\mathrm{V}}_{\mathrm{O}_{2}, \text { in }}-\dot{\mathrm{V}}_{\mathrm{O}_{2}, \text { out }}, \\
\dot{\mathrm{V}}_{\mathrm{CO}_{2}, \text { chamber }} & =\dot{\mathrm{V}}_{\mathrm{CO}_{2}, \text { in }}-\dot{\mathrm{V}}_{\mathrm{CO}_{2}, \text { out }}+\dot{\mathrm{V}}_{\mathrm{CO}_{2} \text {, injection }}, \\
\dot{\mathrm{V}}_{\mathrm{N}_{2}, \text { chamber }} & =\dot{\mathrm{V}}_{\mathrm{N}_{2}, \text { in }}-\dot{\mathrm{V}}_{\mathrm{N}_{2}, \text { out }}+\dot{\mathrm{V}}_{\mathrm{N}_{2}, \text { injection }} .
\end{aligned}
$$

The infusion continued until a plateau was approached for $\left[\mathrm{CO}_{2}\right]$ or $\left[\mathrm{O}_{2}\right]$. After termination of the infusion, $\left[\mathrm{CO}_{2}\right]$ and $\left[\mathrm{O}_{2}\right]$ continued to be measured until they approached the environmental values of 0.0003 and 0.2095 respectively. The differential equations were solved numerically with the SimuSolv program (Steiner et al. 1990). This program was also used to estimate statistically the volume of gas in the respiration chamber and the delay between infusion of gas and first signal appearance at the gas analyser based on the kinetics of the change in $\left[\mathrm{CO}_{2}\right]$ and $\left[\mathrm{O}_{2}\right]$. These estimates were included in the model and assumed to be constant for the remainder of the experiment. The volume of gas in the respiration chamber was adjusted for the presence of animals assuming a density of $1.0 \mathrm{~kg} / 1$ for the animals.

\section{Oxygen consumption and carbon dioxide production by pigs}

Six pigs (three castrated Large White males, one Large White boar, one Piétrain boar and one castrated Meishan male) were placed in individual metabolism cages. The animals weighed between 28 and $58 \mathrm{~kg}$ (Table 1) and were fed ad libitum on a diet containing (g/ $\mathrm{kg}$ ): crude protein 220 , starch 440 , fat 36 and neutral-detergent fibre (NDF) 160 . The energy contents of the feed (MJ/kg DM) were 18.1, 15.9 and 15.5 for gross, digestible and metabolizable energy respectively. The animals remained on this diet for at least $10 \mathrm{~d}$ (with the last $4 \mathrm{~d}$ in the respiration chamber) after which they were subject to a $31 \mathrm{~h}$ fast. At the end of this fast, the animals received a single meal of the previously described diet $(30 \%$ of their daily consumption). The animals had free access to water throughout the duration of the experiment. The data used in the present study concerned the change in $\left[\mathrm{O}_{2}\right]$ and $\left[\mathrm{CO}_{2}\right]$ in the respiration chamber from the beginning of the fast to $16 \mathrm{~h}$ after ingestion of the test meal $(47 \mathrm{~h})$.

To provide the animals with their ration and to remove faeces, the respiration chambers had to be opened briefly. The quantities of gas entering $\left(\mathrm{O}_{2}\right)$ or leaving $\left(\mathrm{CO}_{2}\right)$ the chamber were determined from the gas concentration immediately before and after the opening of the respiration chamber and the physical volume of the chamber. The differential equations describing the change in gas concentration were modified accordingly to account for the opening of the chamber.

The model stuctures for $\mathrm{O}_{2}$ consumption and $\mathrm{CO}_{2}$ production were essentially similar and only the former will be used for describing the model. Nevertheless, it is important to note that in modelling the dynamics of gas exchange in the respiration chamber, both $\mathrm{O}_{2}$ consumption and $\mathrm{CO}_{2}$ production have to be modelled simultaneously. Due to dilution effects, the $\left[\mathrm{O}_{2}\right]$ may decrease only because $\mathrm{CO}_{2}$ is being produced.

Total $\mathrm{O}_{2}$ consumption (and $\mathrm{CO}_{2}$ production) by the animal was subdivided into $\mathrm{O}_{2}$ consumption due to resting metabolism, physical activity, and thermic effect of feeding (TEF). Preliminary results indicated that fed animals have a different resting (i.e. constant) $\mathrm{O}_{2}$ consumption to that of fasting animals. The adaptation from the fed resting state $\left(\dot{\mathrm{V}}_{\mathrm{O}_{2} \text {, fed }}\right.$; litres/h) to the fasting resting state $\left(\dot{\mathrm{V}}_{\mathrm{O}_{2} \text {, fasting }}\right.$; litres $\left./ \mathrm{h}\right)$ was described as a firstorder decline with mean adaptation time $\mathrm{T}_{\mathrm{O}_{2} \text {, adaptation }}(\mathrm{h})$. To maintain simplicity of the 
model, the animals were assumed to be initially in a fed resting state which was subject to the first-order decline. The animals attained the fasting metabolic state asymptotically. The resting $\mathrm{O}_{2}$ consumption is then given by:

$$
\dot{\mathrm{V}}_{\mathrm{O}_{2} \text {,resting }}=\dot{\mathrm{V}}_{\mathrm{O}_{2} \text {,fasting }}+\left(\dot{\mathrm{V}}_{\mathrm{O}_{2} \text {, fed }}-\dot{\mathrm{V}}_{\mathrm{O}_{2} \text {,fasting }}\right) \times \exp \left(\frac{-\mathrm{t}}{\mathrm{T}_{\mathrm{O}_{2} \text {,adaptation }}}\right) \text {, }
$$

where $t$ is time after the beginning of the fasting period (i.e. the beginning of the experiment). No corrections to the resting state were made during or after ingestion of the test meal.

$\mathrm{O}_{2}$ consumption due to physical activity $\left(\dot{\mathrm{V}}_{\mathrm{O}_{2} \text {,activity }} ;\right.$ litres/h) was assumed to be constant over the measured period and expressed only when the animal was active (i.e. when at least one of the infrared beams was interrupted for at least $20 \mathrm{~s}$ ).

TEF was defined as the dynamic component of $\mathrm{O}_{2}$ consumption related to intake of a meal (i.e. ingestion, digestion, absorption and metabolism). Some of the components of TEF are associated with a temporary increase in $\mathrm{O}_{2}$ consumption (e.g. ingestion) whereas others result in a more continuous $\mathrm{O}_{2}$ consumption (e.g. absorption and metabolism). Because these components cannot be identified separately, a model was used in which the $\mathrm{O}_{2}$ consumption after the ingestion of the test meal was described as a gamma distribution of time. This type of model has been widely used in describing digesta passage in ruminants (Matis et al. 1989). In the current context, it represents a distribution of time during which $\mathrm{O}_{2}$ will be consumed after ingestion of a meal. On ingestion, feed will enter a compartment $X$ (kg; Fig. 1). The inflow to this compartment is determined by the rate of feed ingestion whereas the outflow is determined by a gamma distribution of residence times. Feed intake was assumed to be constant during a meal (i.e. quantity eaten divided by the duration of the meal) and zero between meals. $\mathrm{O}_{2}$ consumption due to TEF $\left(\dot{\mathrm{V}}_{\mathrm{O}_{2}, \mathrm{TEF}}\right.$; litres $/ \mathrm{h}$ ) was assumed to be proportional to the outflow from $\mathrm{X}$. The gamma-distribution of residence times in compartment $\mathrm{X}$ was solved as a series of compartments (in this case: two) with identical fractional outflow rates $\left(k_{x} ; / h\right)$. Mathematically:

$$
\begin{aligned}
\dot{\mathrm{X}}_{1} & =\text { rate of intake }-\mathrm{k}_{\mathrm{X}} \mathrm{X}_{1}, \\
\dot{\mathrm{X}}_{2} & =\mathrm{k}_{\mathrm{X}} \mathrm{X}_{1}-\mathrm{k}_{\mathrm{X}} \mathrm{X}_{2}, \\
\dot{\mathrm{X}} & =\text { rate of intake }-\mathrm{k}_{\mathrm{X}} \mathrm{X}_{2}, \\
\dot{\mathrm{V}}_{\mathrm{O}_{2}, \text { TEF }} & =\mathrm{O}_{2, \text { TEF }} \mathrm{k}_{\mathrm{X}} \mathrm{X}_{2},
\end{aligned}
$$

where $\mathrm{O}_{2, \text { TEF }}$ is the proportionality factor (litres $\mathrm{O}_{2}$ consumed $/ \mathrm{kg}$ feed ingested). The $\mathrm{X}_{1}$ and $X_{2}$ indicate two sequential compartments to solve the system with a gamma distribution of residence times. The mean residence time in $X$ (i.e. the mean time between ingestion of food and its related $\mathrm{O}_{2}$ consumption) is given by $2 / \mathrm{k}_{\mathrm{X}}$ and the variance of the distribution by $2 /\left(\mathrm{k}_{\mathrm{X}}\right)^{2}$. To simplify interpretation, the model was parametrized to include the mean time between ingestion of a meal and its related $\mathrm{O}_{2}$ consumption $\left(\mathrm{T}_{\mathrm{TEF}}=2 / \mathrm{k}_{\mathrm{X}}\right.$; h) rather than $k_{X}$. $O_{2}$ consumption by the animal (litres/h) is then given by:

$$
\dot{\mathrm{V}}_{\mathrm{O}_{2} \text {, consumption }}=\dot{\mathrm{V}}_{\mathrm{O}_{2} \text {, resting }}+\dot{\mathrm{V}}_{\mathrm{O}_{2} \text {,activity }}+\dot{\mathrm{V}}_{\mathrm{O}_{2} \text {, TEF}} \text {. }
$$

A data table was constructed containing records for time, $\left[\mathrm{O}_{2}\right],\left[\mathrm{CO}_{2}\right]$, and the atmospheric pressure. Because the data table in the program to solve the differential equations was limited to 10000 elements, no more than 2500 records could be used in the data analysis. As the experiment lasted $47 \mathrm{~h}$, mean $\left[\mathrm{O}_{2}\right],\left[\mathrm{CO}_{2}\right]$, and the atmospheric pressure were calculated for $70 \mathrm{~s}$ intervals (based on the $10 \mathrm{~s}$ averages stored on the 


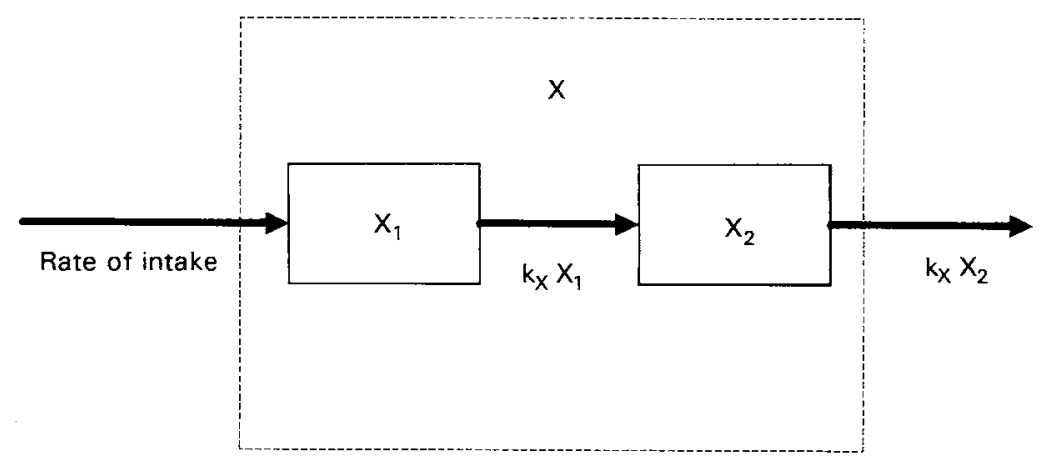

Fig. 1. Compartmental representation describing the dynamics of the thermic effect of feed (TEF). The compartments $\mathrm{X}_{1}$ and $\mathrm{X}_{2}$ (with fractional outflow rate $\mathrm{k}_{\mathrm{X}}, / \mathrm{h}$ ) are used to solve the gamma distribution of time between the ingestion of feed and the resulting $\mathrm{O}_{2}$ consumption and $\mathrm{CO}_{2}$ production. The $\mathrm{O}_{2}$ consumption and $\mathrm{CO}_{2}$ production due to TEF are proportional to the outflow from $\mathrm{X}$ (i.e. $\mathrm{k}_{\mathrm{x}} \mathrm{X}_{2}$ ).

microcomputer). It is evident that for shorter experiments, a smaller time interval can be used.

The system of differential equations (Equations 2) was solved through numerical integration using the Gear's backward difference formulas of the SimuSolv program (Steiner et al. 1990). The integration step-size varied but did not exceed the interval between observations $(70 \mathrm{~s})$. Intermediate values for atmospheric pressure were obtained through smoothed interpolation of the recorded values. Initial values for the volumes of $\mathrm{O}_{2}$, $\mathrm{CO}_{2}$, and $\mathrm{N}_{2}$ were calculated from the first data record and the STP equivalent of the physical volume of the respiration chamber. Initial values for $X_{1}$ and $X_{2}$ were based on the meal intake from the previous day assuming a mean residence time in $X$ of $5 \mathrm{~h}$.

Parameters were estimated by maximization of a $\log$ likelihood function (Bard's likelihood standard reduced model; Steiner et al. 1990) using $\left[\mathrm{O}_{2}\right]$ and $\left[\mathrm{CO}_{2}\right]$ as dependent variables and time, activity, and feed intake as independent variables and assuming a multivariate normal distribution for the observations. The errors were assumed to be constant and uncorrelated from observation to observation, and from response variable to

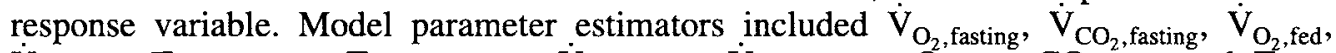

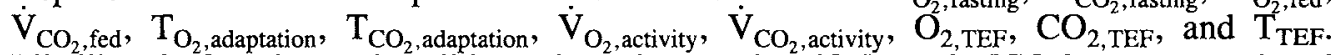
Likelihood functions describing the change in $\left[\mathrm{O}_{2}\right]$ and $\left[\mathrm{CO}_{2}\right]$ were analysed simultaneously due to the interrelationship between gases in the respiration chamber mentioned earlier. Heat production $(\mathrm{kJ} / \mathrm{h})$ was calculated according to Brouwer (1965) excluding urinary- $\mathrm{N}$ and $\mathrm{CH}_{4}$ production. Standard errors of functions of parameters were calculated from the parameter variance-covariance matrix. Normalized sensitivity coefficients were calculated as $\partial \mathrm{y}_{\mathrm{j}} \theta_{\mathrm{k}} / \partial \theta_{\mathrm{k}} \mathrm{y}_{\mathrm{j}}$, where $\mathrm{y}_{\mathrm{j}}$ is the response variable (e.g. $\left[\mathrm{O}_{2}\right]$ ) and $\theta_{\mathrm{k}}$ is the parameter value (e.g. $\mathrm{V}_{\mathrm{O}_{2} \text {,fasting }}$ ) and indicates the percentage change in the response variable due to a percentage change in parameter value.

\section{RESULTS}

An example of the evolution of observed values for $\left[\mathrm{O}_{2}\right]$ together with the physical activity and the duration of ingestion of the test meal is given in Fig. 2. The $\left[\mathrm{O}_{2}\right]$ initially decreases and then increases to attain (approximately) a constant value until the ingestion of the test meal. The initial decrease is due to establishing quasi-equilibrium conditions in the 


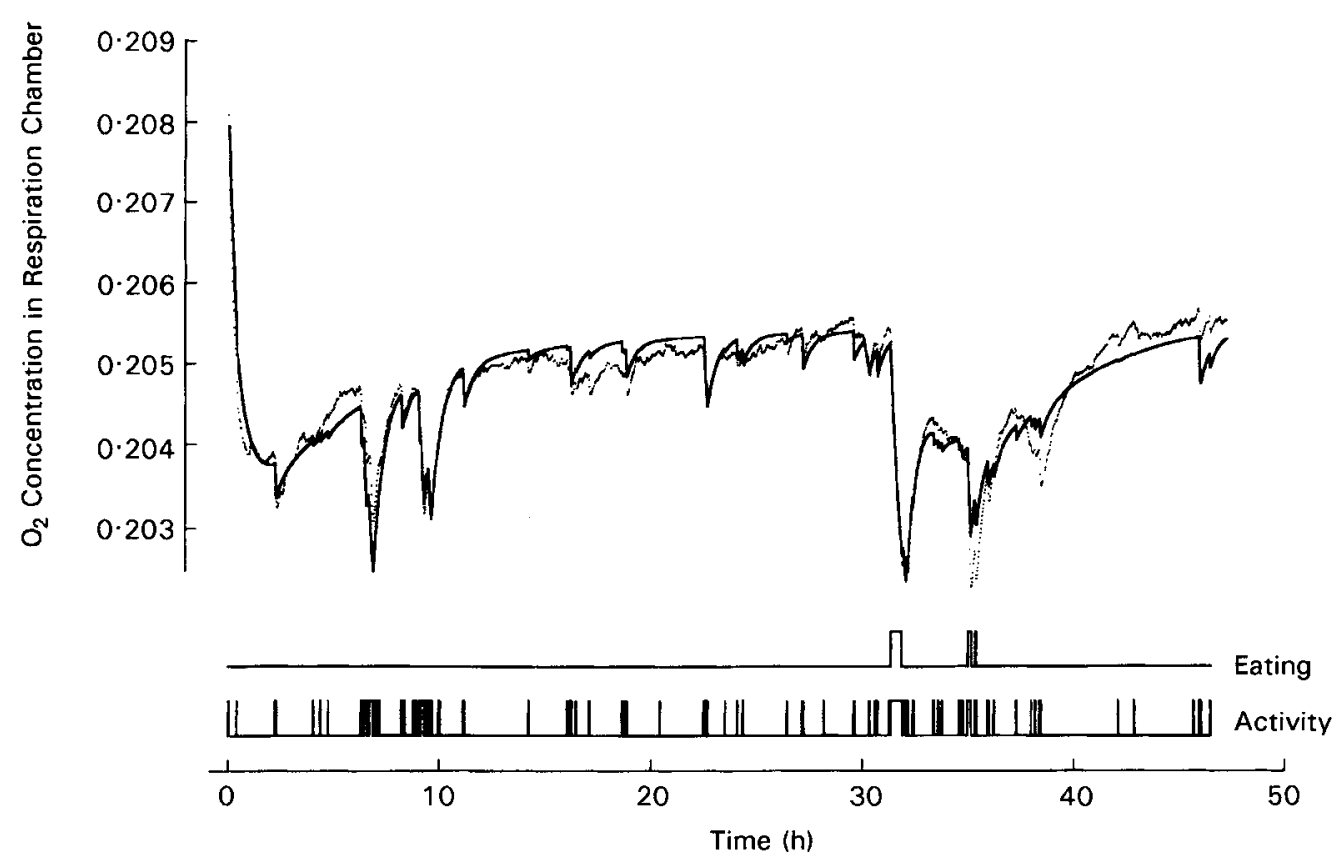

Fig. 2. Dynamics of predicted (__ and observed (.........) $\mathrm{O}_{2}$ concentration in the respiration chamber containing a $40 \mathrm{~kg}$ pig. The animal was subject to a $31 \mathrm{~h}$ fast after which it received a test meal (one third of the daily ad libitum intake). Physical activity (i.e. standing or sitting) and eating are indicated as true (high value) or false (low value).

respiration chamber. The door of the chamber had been open until just before the start of the experiment. As a result, the initial $\left[\mathrm{O}_{2}\right]$ and $\left[\mathrm{CO}_{2}\right]$ were close to environmental values. Due to $\mathrm{O}_{2}$ consumption by the animal, the $\left[\mathrm{O}_{2}\right]$ drops rapidly after the start of the experiment. The kinetics of the initial decline of $\left[\mathrm{O}_{2}\right]$ are determined primarily by the volume of the respiration chamber and the gas extraction rate. If the animal maintained a constant level of $\mathrm{O}_{2}$ consumption, the $\left[\mathrm{O}_{2}\right]$ would attain a plateau whose level would be determined by the level of $\mathrm{O}_{2}$ consumption. In fact, if pressure and temperature in the chamber were constant, the kinetics of the initial decline could have been described by a first-order model. However, the variation in $\left[\mathrm{O}_{2}\right]$ indicates that the $\mathrm{O}_{2}$ consumption is not constant. The increase in $\left[\mathrm{O}_{2}\right]$ between $\mathrm{t}=4 \mathrm{~h}$ and $\mathrm{t}=15 \mathrm{~h}$ indicates that the animal is consuming less $\mathrm{O}_{2}$ than before. In the model, this change is accounted for by a change in resting $\mathrm{O}_{2}$ consumption from a fed towards a fasting state and the diminishing thermic effects of feed ingested before the start of the experiment. Another marked event is the ingestion of the test meal at $\mathrm{t}=31 \mathrm{~h}$ when the animal ate $0.65 \mathrm{~kg}$ in $25 \mathrm{~min}$. The decrease in the $\left[\mathrm{O}_{2}\right]$ was much faster than the increase, indicating that ingestion (or digestion and absorption) of feed results in a prolonged increase in $\mathrm{O}_{2}$ consumption. Other variations in $\left[\mathrm{O}_{2}\right]$ were primarily due to physical activity. It contrast to the statistical assumptions that were made, Fig. 2 shows that residuals were correlated over time. As a result, asymptotic standard errors have to be interpreted with caution.

Table 1 lists some of the observed characteristics for the pigs in the respiration chambers, whereas Table 2 lists the parameter estimates that were obtained from maximization of the $\log$ likelihood function with precision estimates for the model. The model predictions corresponded reasonably well with the observations for both the small and large respiration chamber. The residual standard error was approximately ten times the sensitivity of the gas analyser. The sensitivity coefficients vary dynamically with time. For 
Table 1. Animal characteristics, physical activity and ingestion of a test meal after $31 \mathrm{~h}$ of fasting

\begin{tabular}{lcccccc}
\hline \hline Animal ... & 1 & 2 & 3 & 4 & 5 & 6 \\
\hline Breed & LW & LW & LW & LW & Piétrain & Meishan \\
Type & castrate & castrate & castrate & boar & $\begin{array}{c}\text { boar } \\
\text { castrate }\end{array}$ \\
Weight of pig (kg) & 28 & 39 & 58 & 42 & 42 & 40 \\
Volume of chamber (litres) & 2100 & 2100 & 11700 & 11700 & 2100 & 2100 \\
No. of physical activities & 61 & 74 & 60 & 117 & 65 & 86 \\
Total activity (h) & 2.3 & 2.9 & 3.0 & 3.9 & 4.8 & 5.8 \\
Activities lasting more than 1 min (h) & $2 \cdot 1$ & 2.7 & 2.8 & 3.5 & 4.7 & 5.5 \\
No. of meals & 3 & 3 & 3 & 3 & 1 & 1 \\
Test meal (kg) & 0.59 & 0.75 & 0.94 & 0.70 & 0.57 & 0.64 \\
Duration of eating (h) & 0.96 & 0.71 & 0.69 & 0.59 & 0.72 & 0.61 \\
Initial X ${ }_{1}^{*}(\mathrm{~kg})$ & 0.24 & 0.31 & 0.54 & 0.34 & 0.15 & 0.12 \\
Initial $\mathrm{X}_{2}^{*}(\mathrm{~kg})$ & 0.24 & 0.18 & 0.16 & 0.24 & 0.15 & 0.16 \\
\hline \hline
\end{tabular}

LW, Large White.

* Initial values used in the compartmental representation of a gamma distribution of time between the ingestion of feed and the resulting $\mathrm{O}_{2}$ or $\mathrm{CO}_{2}$ production.

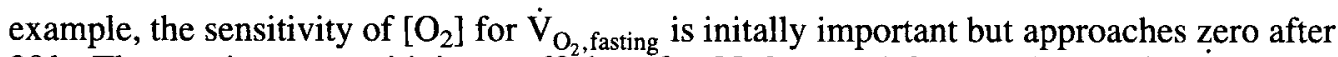
$20 \mathrm{~h}$. The maximum sensitivity coefficient for $\left[\mathrm{O}_{2}\right]$ ranged from $-3.0 \mathrm{E}-2$ for $\dot{\mathrm{V}}_{\mathrm{O}_{2} \text {, fed }}$ to

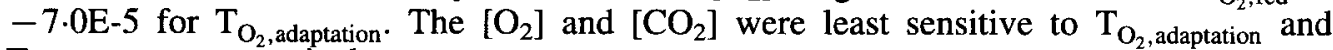
$\mathrm{T}_{\mathrm{CO}_{2} \text {, adaptation }}$ respectively.

The parameter estimates, together with the model described earlier, allow calculation of auxiliary variables such as the heat production $(\mathrm{kJ} / \mathrm{h})$ or $\mathrm{RQ}$. An example of the evolution of the components of $\mathrm{O}_{2}$ consumption is given in Fig. 3. It clearly illustrates the important contribution of resting fasting $\mathrm{O}_{2}$ consumption to the total $\mathrm{O}_{2}$ consumption, and the magnitude of change in $\mathrm{O}_{2}$ consumption due to physical activity.

\section{DISCUSSION}

\section{Calculation method}

Rapid changes in $\mathrm{O}_{2}$ consumption or $\mathrm{CO}_{2}$ production are difficult to detect when using large respiration chambers due to the large volume of gas in the chamber. Traditionally, heat production is calculated based on physical aspects of the gases (temperature, pressure) and the size of the respiration chamber. The generated data (heat production) are regressed $v$. a series of independent variables (e.g. time, activity, eating) using an 'animal' model. Because heat production is a dynamic phenomenon (its units include 'time') and is subject to rapid changes, calculations based on short time intervals can result in noisy data (Brown et al. 1984; McDonald et al. 1988). If a statistical model were to be employed to describe the heat production, the difference between observed and predicted values would be a function of the calculation error (noise) and the true error (accuracy of the model). With short $\partial \mathrm{t}$, the calculation error would be much larger than the true error, rendering model evaluation impossible. To reduce the noise, several signal processing techniques have been proposed including calculation of moving averages (Brown et al. 1984; Sun et al. 1994), fitting cubic splines (Brown et al. 1994), Kalman filtering (Even et al. 1991) and deconvolution analysis of linear systems (McDonald et al. 1988). Nevertheless, the noise observed when $\partial t$ approaches zero is inherent to a system where the calculation of heat production is based on observations. 


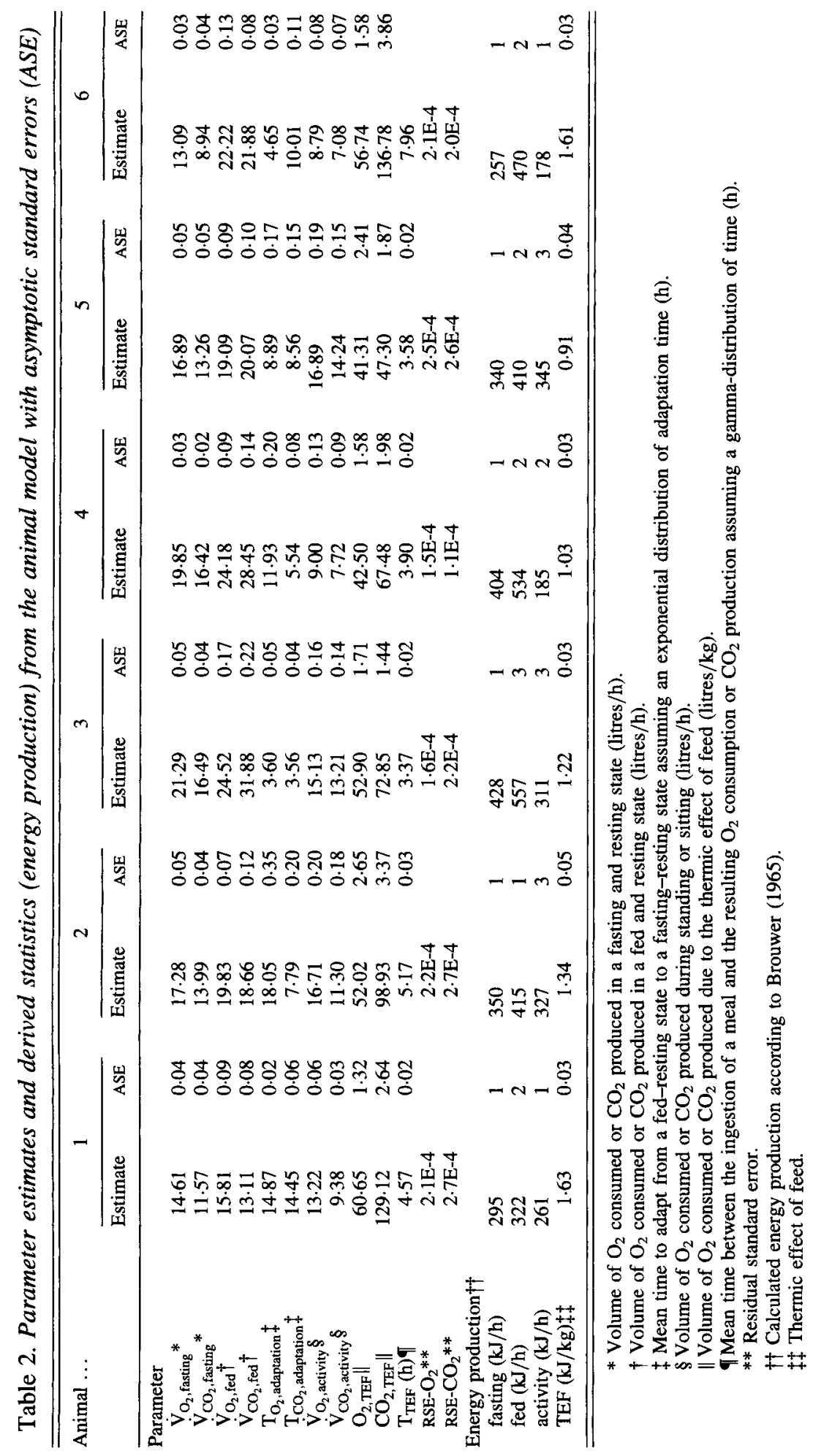




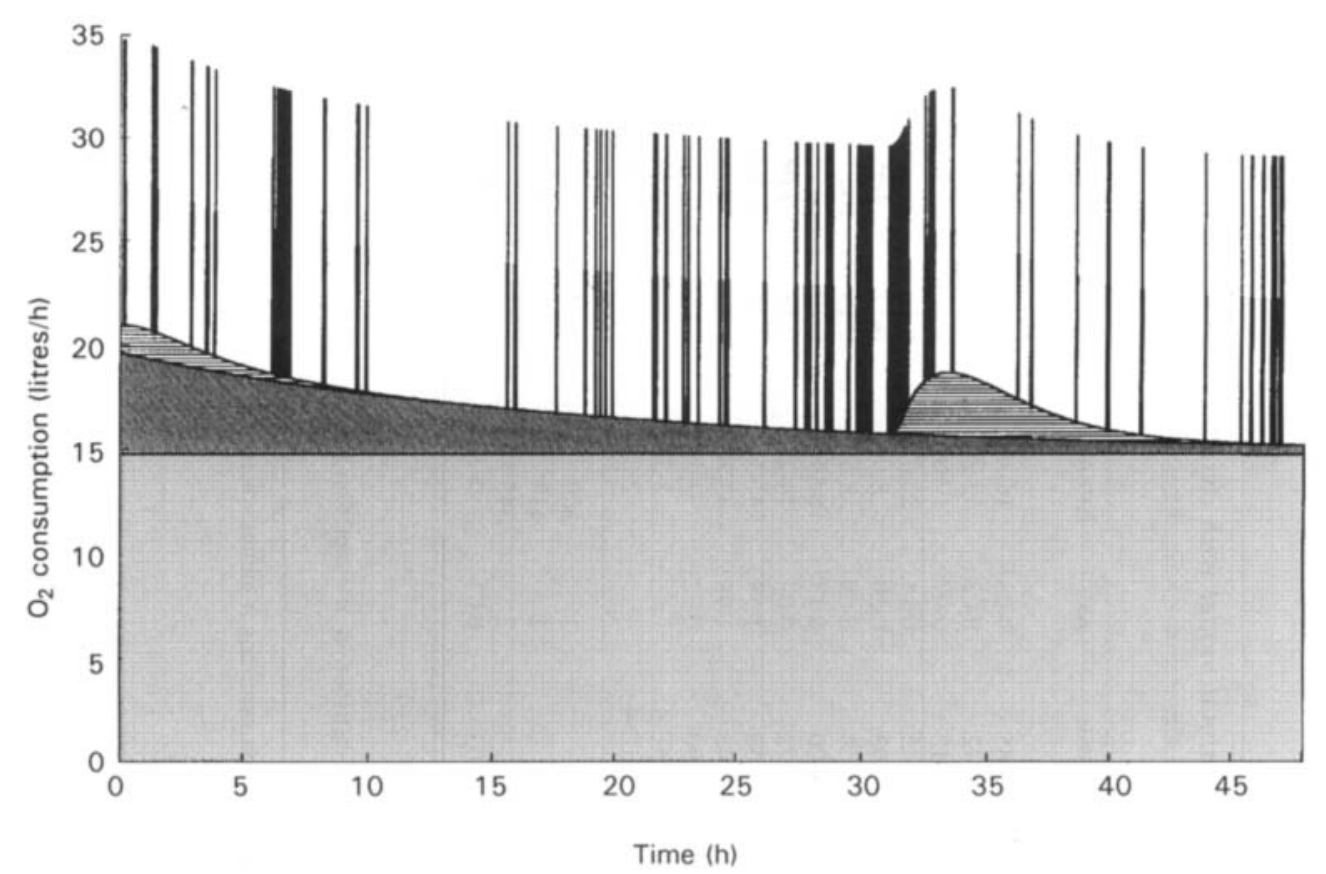

Fig. 3. Components of $\mathrm{O}_{2}$ consumption in a $40 \mathrm{~kg}$ growing pig. The animal was subject to a $31 \mathrm{~h}$ fast after which it received a test meal (one third of the daily ad libitum intake). The components included fasting-resting $\mathrm{O}_{2}$ consumption (歌), the adaptation from a fed-resting to a fasting-resting state (W), the thermic effect of feed (娄) and $\mathrm{O}_{2}$ consumption due to physical activity ( $\mathbf{G}$.

In large respiration chambers, gas concentrations fluctuate less than the calculated gas exchanges or heat production. In the proposed method, a statistical model was employed to predict directly the change in $\left[\mathrm{O}_{2}\right]$ and $\left[\mathrm{CO}_{2}\right]$ in the respiration chamber. The model was based on a series of differential equations which were integrated numerically. With decreasing $\partial t$, the solution of numerical integration approaches the true solution of a system of differential equations. As a result, precision of the prediction is increased and the difference between observed and predicted values is determined primarily by the appropriateness of the proposed model. The method has the advantage that short-term dynamics of energy metabolism can be studied with few numerical constraints. Nevertheless, the combination of short $\partial t$ (e.g. $<1 \mathrm{~s})$ between measurements and long duration of the experiment (several days) results in large data matrices that have to be analysed statistically. Statistical analysis of an experiment on a SUN SPARCStation 10 typically required less than $20 \mathrm{~min}$ of the central processing unit (CPU). With the rapid development of computer hardware and software, it is unlikely that data matrix size and computer CPU requirement will impose major barriers for the type of analysis proposed here.

\section{Resting metabolism}

Data on feed intake of the day preceding the start of the experiment indicated that three animals (2, 3 and 4) had eaten shortly before the withdrawal of food, which resulted in higher initial values for $X_{1}$. Although this was accounted for in the calculation of TEF, no adjustments were made for the resting metabolic state. In other words, the last meal for the 
other animals occurred earlier, and at the start of the experiment these animals were 'fasting voluntarily'. Therefore, $\dot{\mathrm{V}}_{\mathrm{O}_{2} \text {,fed }}$ and $\dot{\mathrm{V}}_{\mathrm{CO}_{2} \text {, fed }}$ have to be interpreted with caution as it is difficult to define precisely a point in time at which animals will start adapting their resting metabolism.

The mean adaptation time from a fed resting state to a fasting resting state was $10.3 \mathrm{~h}$ for $\mathrm{O}_{2}$ and $8.3 \mathrm{~h}$ for $\mathrm{CO}_{2}$ but this was highly variable between animals. The $\left[\mathrm{O}_{2}\right]$ and $\left[\mathrm{CO}_{2}\right]$ are relatively insensitive to the adaptation time even though the asymptotic standard errors for $\mathrm{T}_{\mathrm{O}_{2} \text {,adaptation }}$ and $\mathrm{T}_{\mathrm{CO}_{2} \text {, adaptation }}$ are small. The adaptation time will play a role during the first few hours of the experiment. During these hours, the most important source of variation in $\left[\mathrm{O}_{2}\right]$ and $\left[\mathrm{CO}_{2}\right]$ is the closing of the respiration chamber which is controlled by constants such as the volume of the respiration chamber and air extraction rate. As a result, the adaptation from the fed to a fasting state only accounts for a small proportion of the observed variation in gas concentration. The limited sensitivity of the gas concentrations for the adaptation time indicates that the model and parameters that are used to describe the adaptation from a fed to a fasting state have to be interpreted with caution. Nevertheless, suppression of the adaptation part of the model (i.e. assuming that $\dot{\mathrm{V}}_{\mathrm{O}_{2} \text {, fasting }}=\dot{\mathrm{V}}_{\mathrm{O}_{2} \text {, fed }}$ and

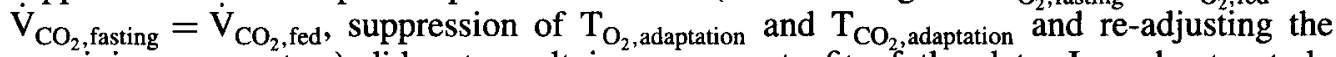
remaining parameters) did not result in an accurate fit of the data. In order to study precisely the adaptation from a fed to a fasting state, it is important to minimize the variation in gas concentrations due to external sources. Opening of the respiration chamber should therefore be limited as much as possible.

For some of the animals, the observed $\left[\mathrm{O}_{2}\right]$ was consistently slightly lower than predicted between 12 and $24 \mathrm{~h}$ after the start of the experiment. The observed $\left[\mathrm{O}_{2}\right]$ remained stable or even decreased whereas the model predicted an increase in $\left[\mathrm{O}_{2}\right]$ in the respiration chamber due to the reducing $\mathrm{O}_{2}$ consumption when adapting from the fed to the fasting-resting state. Although total heat production is generally reduced after prolonged fasting, there are indications that heat production in human subjects increases during the first 2 d of starvation (Elia, 1992; Webber \& Macdonald, 1994; Macdonald \& Webber, 1995) compared with an overnight fast. This has been attributed to increased gluconeogenesis, ketogenesis and differences in energetic efficiencies between glucose and fat utilization for ATP synthesis.

Both $\mathrm{O}_{2}$ consumption and $\mathrm{CO}_{2}$ production decreased during fasting, although the latter decreased to a greater extent (Table 2). As a result, the resting RQ will be lower in the fasting state than in the fed state. The fact that $R Q_{\text {fasting }}$ is less than 1 indicates that lipids and/or proteins are oxidized to produce energy. Differences in resting metabolism between animals are partially due to differences in (metabolic) body weight. The fasting energy production (at zero activity) averaged $0.51(\mathrm{SD} 0.07) \mathrm{MJ} / \mathrm{d}$ per $\mathrm{kg}^{0.75}$ which was intermediate between values found by McDonald et al. $\left(1988 ; 0.45 \mathrm{MJ} / \mathrm{d}\right.$ per kg $\left.{ }^{0.75}\right)$ and Bernier \& Noblet (1996; 0.55 MJ/d per $\mathrm{kg}^{0.75}$ ) for pigs of similar weight.

\section{Activity}

During the $47 \mathrm{~h}$ period, between sixty and 117 periods of activity lasting more then $20 \mathrm{~s}$ were recorded; the longest period was associated with the ingestion of the test meal (Table 1). The $\mathrm{O}_{2}$ consumption and $\mathrm{CO}_{2}$ production due to physical activity were of similar magnitude to those of the fasting state. In other words, a fasting animal doubles its heat production when it is sitting or standing. The energy produced during activity averaged $16.8(\mathrm{SD} 5.0) \mathrm{kJ} / \mathrm{kg}^{0.75}$ body weight (BW) per h $(6.7$ (SD 2.2) $\mathrm{kJ} / \mathrm{kg} \mathrm{BW}$ per h), a value close to those compiled by Noblet et al. (1993) for pigs, ranging in weight between 27 and 
$208 \mathrm{~kg}$. McDonald et al. (1988) reported that in fasting pigs, physical activity increased heat production by $95 \%$ for events lasting longer than 4 min and $119 \%$ for shorter events (standing activities lasted $7 \mathrm{~min} 5 \mathrm{~s}$ on average whereas sitting never lasted longer than $4 \mathrm{~min}$ ). In contrast, the average duration of sitting or standing activities in the present experiment was $3 \mathrm{~min}$ and a total of only $3.8 \mathrm{~h}$ activity was observed during the $47 \mathrm{~h}$ experiment. These results indicate that in growing pigs the limited contribution of activity to the total energy production is due more to the duration than to the energetic cost of activity.

In the current experiment, a constant $\mathrm{O}_{2}$ consumption and $\mathrm{CO}_{2}$ production was assumed during physical activity. Specific actions such as standing up and lying down could have been included in the model but were not considered here. There are indications (McDonald et al. 1988) that the energy expenditure during standing is far from constant due to movement, raising and lowering of the head and investigative behaviour. Also during lying down, stretching and positional changes may result in a different heat production. To account for the type of the activity, observation systems other than the ones used in this experiment have to be used.

The marginal RQ for activity $\left(\dot{\mathrm{V}}_{\mathrm{CO}_{2} \text {, activity }} / \dot{\mathrm{V}}_{\mathrm{O}_{2} \text {,activity }}\right)$ averaged 0.79 which is similar to the $R Q$ during fasting (average 0.78 ). This indicates that fatty acids (the contribution of protein oxidation is generally considered insignificant during mild exercise; Roberts et al. 1996) were the primary energy source for activity. Another explanation for the low marginal RQ for activity may be the bicarbonate transport in the blood. The $\mathrm{CO}_{2}$ resulting from substrate oxidation may have remained dissolved in the blood and been released from the lungs later than detection of the (relatively) short-duration activity.

\section{Thermic effect of feed}

Although pigs in the present study consumed the test meal in two or three separate meals, more than $87 \%$ was consumed during the first meal. In the current experiment, $6.9 \%$ of the gross energy was used for TEF (8.3\% ME), a value similar to that found in adult human subjects (Piers et al. 1992).

The mean duration of TEF was $4.8 \mathrm{~h}$. However, the distinction between TEF and fasting (or fed) resting metabolism is arbitrary. The function chosen to describe the dynamics of TEF aggregates events ranging from instantaneous changes in energy expenditure (e.g. ingestion) to more gradual ones (e.g. substrate assimilation). The latter may also be partially accounted for in the resting metabolism. As a result of this aggregation, no mechanistic interpretation should be attributed to this function other than an empirical description of time between the intake of feed and the resulting heat production. We also tried to describe the dynamics of TEF by a first-order exponential function, but this function over-estimated TEF during the first hours after ingestion of a meal (the maximum energy expenditure for a first-order model

is predicted at the ingestion of the meal). Reed \& Hill (1996) used the model $y=A+B t \exp (-t / C)$ to describe the dynamics of TEF. The model used here, which analytically can be described as $\mathrm{y}=\mathrm{O}_{2, \mathrm{TEF}} \mathrm{X}_{1 \text {,initial }}\left(1 / \mathrm{T}_{\mathrm{TEF}}\right)^{2} \mathrm{t} \exp \left(-\mathrm{t} / \mathrm{T}_{\mathrm{TEF}}\right)^{2}$, is a special case of that used by Reed \& Hill (1996) (i.e., $A=0, B=O_{2, T E F} X_{1, \text { initial }}\left(1 / T_{T E F}\right)^{2}$, and $\mathrm{C}=\mathrm{T}_{\mathrm{TEF}}$ ). It has the advantage that it can be written as a compartmental system, which simplifies solution if is to be used to describe ingestion of several meals during a day.

The marginal RQ for TEF averaged 1.76 causing the $R Q$ to rise during digestion, absorption and assimilation of a meal. Although not often observed in human subjects, RQ values greater than unity are commonly observed in growing animals on low-fat, high- 
carbohydrate diets (Jakobsen \& Thorbek, 1991). Energy from carbohydrate supplied in excess of oxidation and glycogen storage repletion has to be stored as fat. Lipogenesis is composed of the conversion of glucose to fatty acid $(\mathrm{RQ} \infty)$ and glucose oxidation to regenerate NADPH (RQ1). Depending on the stoichiometry of the latter, the RQ for de novo fatty acid synthesis from glucose has been reported to range from 1.9 to 9.6 (Elia \& Livesey, 1988).

\section{Strengths, weaknesses and the future of modelling}

The model proposed here was based on three main components (resting, activity, and thermic effect of feeding). Although these components explained a large part of the variation, some systematic deviations between observations and predictions were apparent (Fig. 2). Some of these deviations may be attributed to the adaptation from a fed-resting state to a fasting-resting state. This adaptation is a complex one, and further refinement of the model would require additional observations (e.g. blood glucose and free fatty acid levels) in order to explain this adaptation physiologically. Other deviations between observed and predicted values may be attributed to the all-or-none notion of physical activity that was adopted for the model (i.e. standing or lying).

An important thing to consider is that the proposed model is a data analysis tool and not a simulation model. The goal is not to obtain the best fit of the data per se, but to obtain the best fit of a mechanistic model given a limited number of independent variables. The deviations between the observed and predicted values may be used to guide further research in this area, but do not exclude analysis of the current model parameters (although caution is required).

In the traditional analysis method, one could calculate energy production without a model (other than the assumptions made in the calculations) and visually evaluate the results. In the method proposed here, one is forced specifically to define a model in order to interpret the changing $\left[\mathrm{O}_{2}\right]$ and $\left[\mathrm{CO}_{2}\right]$ in the respiration chamber. Nevertheless, it is questionable whether a similar detailed analysis could have been performed with the classical methods. The problem of 'noisy data' would make analysis of physical activity more difficult and would probably mask some of the systematic deviations between the observed and predicted values seen here.

In conclusion, a (compartmental and statistical) modelling tool is presented to analyse dynamically and compartmentalize heat production in swine. Parameter estimates obtained from the model were coherent with current biochemical and physiological knowledge. Although the model that is used to explain the observed variation in gas concentrations has to be adapted to specific experimental conditions, the proposed methodology has general applicability. For instance, in animal production it may be used to further refine energy systems or energy requirements.

\section{REFERENCES}

Bernier, J. F. \& Noblet, J. (1996). Fasting heat production of Large White and Meishan growing pigs as influenced by environmental temperature. Journal of Animal Science 74, Suppl. 1, 180.

Brouwer, E. (1965). Report of sub-committee on constants and factors. In Energy Metabolism. Proceedings of the 3rd Symposium held at Troon, Scotland, May 1964, pp. 441-443 [K. L. Blaxter, editor]. London: Academic Press.

Brown, D., Cole, T. J., Dauncey, M. J., Marrs, R. W. \& Murgatroyd, P. R. (1984). Analysis of gaseous exchange in open-circuit indirect calorimetry. Medical and Biological Engineering and Computing 22, 333-338.

Elia, M. (1992). Effect of starvation and very low calorie diets on protein-energy interrelationships in lean and obese subjects. In Protein-energy Interactions. Proceedings of an $1 / D / E / C / G$ Workshop held at Waterville 
Valley, NH, USA, October 21-25 1991, pp. 249-284 [N. S. Scrimshaw and B. Schürch, editors]. Lausanne, Switzerland: I/D/E/C/G, c/o Nestlé Foundation.

Elia, M. \& Livesey, G. (1988). Theory and validity of indirect calorimetry during net lipid synthesis. American Journal of Clinical Nutrition 47, 591-607.

Even, P. C., Perrier, E., Aucouturier, J.-L. \& Nicolaïdis, S. (1991). Utilization of the method of Kalman filtering for performing the on-line computation of background metabolism in the free-moving, free-feeding rat. Physiology and Behavior 49, 177-187.

Jakobsen, K. \& Thorbek, G. (1991). The respiratory quotient in relation to fat retention from carbohydrates or lipids in growing pigs. In Energy Metabolism of Farm Animals. Proceedings of the 12th Symposium held at Kartause Ittingen, Switzerland, September 1-7 1991, pp. 126-129 [C. Wenk and M. Boessinger, editors]. Zurich: Juris Druck + Verlag.

Macdonald, I. A. \& Webber, J. (1995). Feeding, fasting and starvation: factors affecting fuel utilization. Proceedings of the Nutrition Society 54, 267-274.

McDonald, T. P., Jones, D. D., Barrett, J. R., Albright, J. L., Miles, G. E., Nienaber, J. A. \& Hahn, G. L. (1988). Measuring the heat increment of activity in growing-finishing swine. Transactions of the American Society of Agricultural Engineers 31, 1180-1186.

McLean, J. A. \& Watts, P. R. (1976). Analytical refinements in animal calorimetry. Journal of Applied Physiology 40, 827-831.

Matis, J. H., Wehrly, T. E. \& Ellis, W. C. (1989). Some generalized stochastic compartment models for digesta flow. Biometrics 45, 703-720.

Noblet, J., Shi, X. S. \& Dubois, S. (1993). Energy cost of standing activity in sows. Livestock Production Science 34, 127-136.

Piers, L. S., Soares, M. J. \& Shetty, P. S. (1992). Thermic effect of a meal. 2. Role in chronic undernutrition. British Journal of Nutrition 67, 177-185.

Reed, G. W. \& Hill, J. O. (1996). Measuring the thermic effect of food. American Journal of Clinical Nutrition 63, 164-169.

Roberts, T. J., Weber, J. M., Hoppeler, H., Weibel, E. R. \& Taylor, C. R. (1996). Design of the oxygen and substrate pathways. II. Defining the upper limits of carbohydrate and fat oxidation. Journal of Experimental Biology 199, 1651-1658.

Steiner, E. C., Rey, T. D. \& McCroskey, P. S. (1990). SimuSolv - Modelling and Simulation Software. Midland, MI: The Dow Chemical Company.

Sun, M., Reed, G. W. \& Hill, J. O. (1994). Modification of a whole room indirect calorimeter or measurement of rapid changes in energy expenditure. Journal of Applied Physiology 76, 2686-2691.

Vermorel, M., Bouvier, J.-C., Bonnet, Y. \& Fauconneau, G. (1973). Construction et fonctionnement de 2 chambres respiratoires du type «circuit ouvert" pour jeunes bovins (Construction and operation of two opencircuit respiration chambers for young cattle). Annales de Biologie Animale, Biochemie, Biophysique 13, 659681.

Verstegen, M. W. A., van der Hel, W., Brandsma, H. A., Henken, A. M. \& Bransen, A. M. (1987). The Wageningen respiration unit for animal research: a description of equipment and its possibilities. In Energy Metabolism in Farm Animals. Effects of Housing, Stress and Disease. pp. 21-48 [M. W. A. Verstegen and A. M. Henken, editors]. Dordrecht: Martinus Nijhoff Publishers.

Webber, J. \& Macdonald, I. A. (1994). The cardiovascular, metabolic and hormonal changes accompanying acute starvation in men and women. British Journal of Nutrition 71, 437-447. 